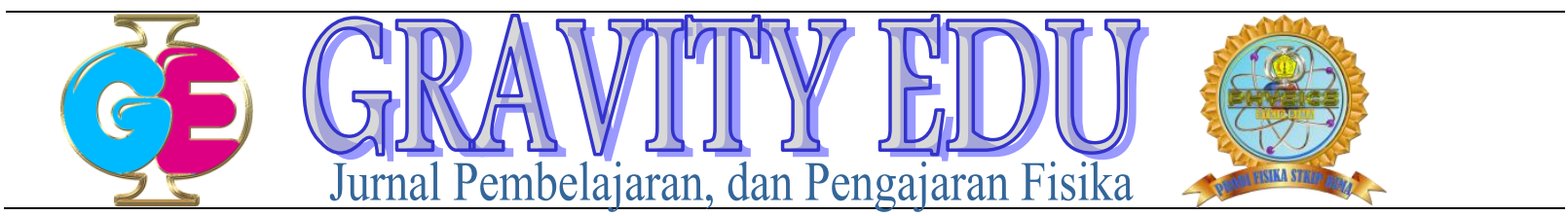

\title{
Sistem Lampu Otomatis Berbasis Arduino Uno Menggunakan Modul Sensor PIR HC 501
}

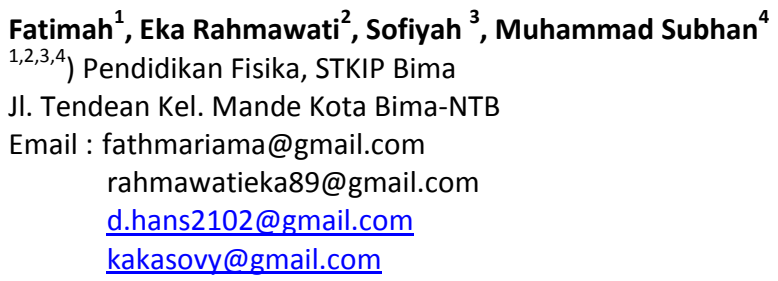

\begin{abstract}
ABSTRAK : Penelitian ini bertujuan membuat rancangan sistem lampu otomatis berbasis arduino uno menggunakan modul PIR HC 501. Hasil pengujian pembuatan alat menunjukkan bahwa sistem kerja rangkaian lampu otomatis yang didasarkan terhadap ruangan yang memiliki sistem input yang terhubung pada Arduino Uno, sistem yang dimiliki yakni sensor Passive Infra Red (PIR) sebagai input sistem yang otomatis yang bertanggung jawab terhadap pembacaan objek pada saat manusia terdeteksi masuk kedalam satu ruangan melalui radiasi infra red yang dihasilkan objek tersebut. Arduino Uno mendapat input dari sensor Passive Infra Red (PIR) kemudian akan diteruskan di relay yang menghasilkan output berupa lampu ruangan yang menyala yang akan distabilkan oleh infra red pada saat penelitian dilakukan percobaan sebanyak 3 kali dengan variasi jarak yang berbeda yaitu jarak 1 meter, 2 meter, 3 meter, 4 meter, dan 5 meter dan variasi sudut yang berbeda pula yaitu $0^{\circ}, 30^{\circ}, 60^{\circ}$. Pada jarak 1 dan 2 meter lampunya menyala dengan waktu respon yang berbeda yaitu 5,206 dan 8,37 detik, sedangkan pada jarak 3 dan 4 meter pada percobaan pertama lampu tidak menyala karna sensor tidak merespon adanya infra merah,sedangkan di percobaan kedua dan ketiga lampunya menyala dengan vafiasi waktu yaitu 5,81 detik dan 5,10 detik, dan pada jarak 5 meter dengan 3 kali percobaan lampunya menyala dengan variasi waktu yakni 3,18 detik. Dan untuk sudut sendiri semakin besar sudutnya maka respon sensor terhadap objek sangat lemah bahkan tidak bisa medeteksi adanya infra merah pada objek. Berdasarkan hasil penelitian pada jarak 1 meter dan sudut $0^{\circ}$ yakni tepat didepan sensor waktu sensor mendeteksi adanya infra merah pada objek butuh beberapa gerakan objek, sehingga sensor dapat mendeteksi objek tersebut, sedangkan semakin lebarnya sudut daya deteksi sensor sangat lemah sehingga tidak dapat mendeteksi adanya infra merah
\end{abstract}

Kata kunci: Arduino Uno, lampu otomatis, sensor PIR.

\section{ABSTRACK}

This study aims to design an arduino uno-based automatic light system using pir HC 501 module. The results of the tool design test, show that the working system of the automatic light circuit based on the room has an input system connected to the Arduino Uno. Passive-Infra-Red (PIR) sensor system as an automatic input system responsible for the reading of objects when humans are detected entering a room through infra-red radiation produced by the object. Arduino Uno gets input from passive infra red sensor (PIR) then will be passed on in relay that produces output in the form of room lights that will be stabilized by infra red at the time of the study conducted experiments as many as 3 times with different distance variations, distances of 1 meter, 2 meters, 3 meters, 4 meters, and 5 meters and different angle variations are $0^{\circ}$, $30^{\circ}, 60^{\circ}$. At distances of 1 and 2 meters the lights are lit with different response times of 5,206 and 8.37 seconds, while at a distance of 3 and 4 meters on the first try the light does not turn on because the sensor does not respond to the presence of infrared, while in the second and third experiment the lights are lit with a time vafiation of 5.81 seconds and 5.10 seconds, and at a distance of 5 meters with 3 experiments the lights are on with a time variation of 3.18 seconds. And for the angle itself the larger the angle, the sensor's response to the object is very weak and can not even detect the presence of infrared on the object. the results of the study at a distance of 1 meter and an angle of $0{ }^{\circ}$ that is right in front of the sensor time sensor detects the presence of infrared on the object needs some movement of the object, so that the sensor can detect the object, while the wider the detection power angle of the sensor is so weak that it cannot detect the presence of infrared 


\section{PENDAHULUAN}

Perkembangan teknologi yang sangat pesat saat ini membawa kita menuju era modernisasi. Hampir seluruh aspek kehidupan manusia sangat bergantung pada teknologi, hal ini dikarenakan teknologi diciptakan untuk membantu mempermudah manusia dalam menyelesaikan suatu aktifitas/pekerjaan. Aktifitas yang tinggi terkadang membuat manusia melupakan hal-hal kecil yang seharusnya lakukan. Hal kecil sekalipun terkadang dapat berakibat buruk.

Pengendalian pada alat-alat listrik khususnya lampu atau penerangan merupakan hal yang penting dalam pengelolaan energi dalam suatu tempat, misalnya saja di rumah, gedung perkantoran ataupun area lainnya yang lebih luas dan mempunyai banyak lampu. Otomatisasi atau pengendalian terhadap suatu komponen elektronik ataupun listrik menjadi sangat penting di masa sekarang ini dimana keefisienan dan kecepatan dituntut dalam segala bidang agar tercapai suatu sistem yang handal serta memudahkan dalam penggunaannya. Misalnya saja pada suatu sistem pengendalian lampu pada suatu gedung atau rumah.

Untuk mengatasi masalah ini perlu adanya perencanaan yang tepat, sehingga timbul pemikiran untuk memanfaatkan komputer guna mengendalikan peralatan listrik tersebut dalam hal ini lampu ruangan sehingga pengontrolan nyala padamnya lampu ruangan tersebut tidak lagi dilakukan secara manual tetapi dapat dilakukan melalui fasilitas komputer dan sensor PIR. Sensor PIR adalah Pasive Infra Red yang dapat mendeteksi pergerakan, dalam hal ini sensor PIR banyak digunakan untuk mengetahui apakah ada pergeraakan manusia dalam daerah yang mampu dijangkau oleh sensor PIR. Sensor PIR dibuat dengan sebuah sensor pyroelectric sensor yang dapat mendeteksi tingkat radiasi infrared.

Dengan adanya sistem pengontrolan ini diharapkan dapat meningkatkan efisiensi penggunanan energi listrik dan meningkatkan efisiensi kerja manusia sehingga lebih menghemat waktu serta dapat menekan biaya operasional, maka dari itu penulis bermaksud untuk membuat suatu alat yang dapat berkerja secara otomatis untuk menyalakan dan memadamkan lampu. Umumnya alat yang telah dikembangkan saat ini menggunakan satu sensor saja dengan judul "Sistem Lampu Otomatis Berbasis Ardiuno Menggunakan Modul PIR HC - 501".

Penerapan Sensor Passive Infrared (PIR) juga sudah diterapkan Pada Pintu Otomatis Di PT LG Electronic Indonesia [1], pada penelitian ini bertujuan untuk mengetahui prinsip kerja dari sensor PIR pada pintu otomatis, jarak maksimal yang dideteksi sensor PIR, dan juga waktu respon yang dibutuhkan oleh sensor PIR terhadap objek yang dideteksi. Sensor PIR dapat diimplementasikan pada peralatan elektronik berbasis mikrokontroler (Ahadiah, S., Muharnis, dan Agustiawan, 2017). Sistem penerangan dalam suatu ruangan dapat menghindari lampu yang menyala secara sia-sia jika tidak ada aktifitas di dalamnya. Selain itu kipas angin juga dapat dikendalikan secara otomatis menggunakan sensor PIR. Sensor PIR dapat digunakan bersamaan dengan sensor lainnya, seperti sensor suhu dan sensor suara yang digunakan untuk pengendali lampu otomatis (Lukman, Junaedy, dan Rieuwpassa, 2018). Penelitian ini bertujuan untuk mengimplementasikan sensor gerak, sensor suhu dan sensor suara untuk penyalaan lampu secara otomatis pada toilet. Sistem ini berfungsi untuk menyalakan lampu secara otomatis saat ada orang yang memasuki toilet dan mematikan lampu secara otomatis saat tidak ada orang di dalam toilet tersebut. Perangkat keras yang digunakan adalah mikrokontroler Arduino Uno, sensor gerak PIR, sensor suhu MLX90614, sensor suara KY - 038, relay, dan lampu LED 3W. Perangkat lunak untuk pembuatan program yaitu Arduino IDE dimana bahasa pemrograman yang digunakan yaitu bahasa pemrograman C. Hasil pengujian menunjukkan bahwa sensor PIR dapat mendeteksi gerakan orang yang memasuki atau meninggalkan ruangan sedangkan sensor KY-038 dan sensor MLX90614 masih memiliki kelemahan dalam pendeteksian suara dan suhu. Pada penelitian ini penulis menggunakan metode pengumpulan data menggunakan metode wawancara dan mencari jurnal terbaru sebagai bahan materi di jurnal yang akan dibuat mengenai cara kerja sensor passive infrared. Hasil dari penelitian yaitu Cara kerja sistem sensor PIR adalah ketika seseorang berjalan melewati sensor, sensor akan menangkap pancaran sinar inframerah pasif yang dipancarkan oleh tubuh manusia yang memiliki suhu yang berbeda dari lingkungan sehingga menyebabkan material pyroelectric bereaksi menghasilkan arus listrik karena adanya energi panas yang dibawa oleh sinar infra merah pasif tersebut. Kemudian sebuah sirkuit amplifier yang ada menguatkan arus tersebut yang kemudian dibandingkan oleh comparator sehingga menghasilkan output.

Penelitian yang dilakukan oleh [2], "Rancang Bangun Lampu Otomatis. Dengan Sensor Passive Infra Red (PIR) Berbasis Raspberry Pi, Sejalan dengan pesatnya perkembangan di bidang teknologi maka jumlah kebutuhan daya listrik cenderung naik dengan pesat. Peningkatan kebutuhan ini dapat diakibatkan karena masyarakat makin banyak menggunakan teknologi baru seperti, tetapi dapat juga karena adanya pemborosan pemakaian listrik. Salah satu bentuk pemborosan listrik yang seringkali terjadi adalah lampu yang lupa dipadamkan saat tidak digunakan karena menggunakan saklar manual untuk menghidupkan 
dan memadamkan lampu. Untuk itu penelitian ini akan membangun suatu sistem lampu yang dioperasikan dengan saklar otomatis agar dapat memberikan solusi penghematan daya listrik bagi masyarakat di Kota Palu. Jenis penelitian ini adalah kualitatif dengan pendekatan eksperimen. Pengumpulan data melalui observasi, studi pustaka, dan forum diskusi. Perancangan lampu otomatis dengan sensor PIR berbasis Raspberry Pi 2 model B menggunakan metode extreme programing. Hasil penelitian ini menunjukkan sistem lampu otomatis dengan sensor PIR berbasis Raspberry Pi 2 model B dapat bekerja dengan baik dan dapat diterapkan dalam kehidupan seharihari. Untuk itu, penelitian kedepan perlu menggunakan alat dan sensor mempunyai kualitas tinggi sehingga dalam pemakaian jangka panjang tidak terlalu sering melakukan perawatan dan untuk ruangan yang lebih luas memperlukan penambahan jumlah sensor sesuai kebutuhan.

\section{METODE PENELITIAN}

Pengumpulan data penelitian menggunakan metode eksperimen mengambil data dari data sheet komponen, serta refrensi level jarak PIR sensor.

\section{Perancangan Sistem Lampu Otomatis Menggunakan Arduino Dan Sensor PIR}

Prinsip kerja dari rangkaian ini adalah Arduino Uno akan membaca input dari sensor PIR. Apabila sensor PIR mendeksi adanya gerakan maka pergerakan ini dapat dideteksi dengan mengecek logika high pada pin output sensor sehingga arduino akan memerintah relay untuk hidup dan nyalakan lampu. Berikut adalah gambar rangkaian proyek saklar otomatis dengan menggunakan sensor PIR HCSR501 yang dibuat dengan software fritzing.

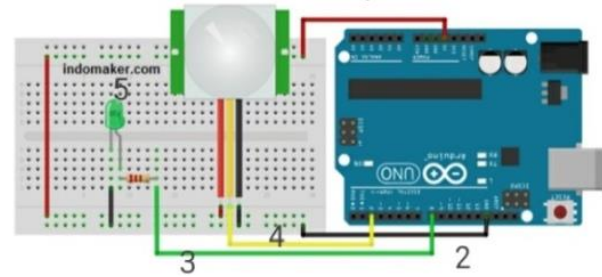

Gambar 1. Rangkaian

Keterangan :

1. Kaki pin $5 \mathrm{~V}$ di arduinodihubungkanke kaki pin VCC pada sensor PIR

2. Kaki pin 2 di arduinodihubungkan di kaki pin OUT pad sensor PIR

3. Kaki pin GND di arduinodihubungkan di kaki pin GND pada sensor PIR

4. Kaki pin 4 arduinodihubungkan di kaki pin IN 1 pada relay.

\section{Alur Program Sistem}

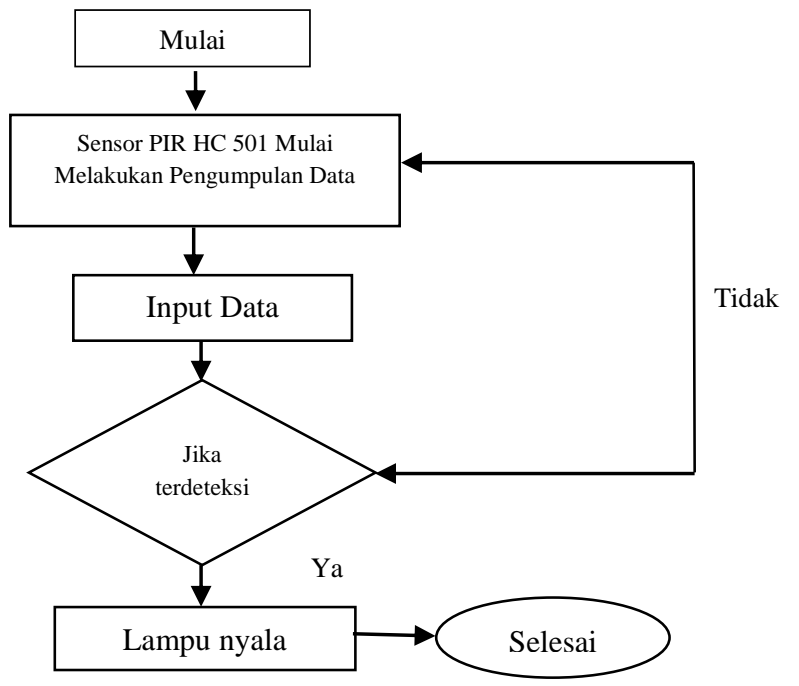

Gambar 2. Bagan 1 Flowchart sistem lampu otomatis

Berdasarkan flowchart di atas, ketika sebuah nilai angka dimasukkan kedalam sistem melalui layar serial monitor, kemudian informasi ini akan disampaikan ke modul Arduino UNO R3 untuk selanjutnya diproses. Hasil pengolahan modul Arduino UNO R3 kemudian dikirimkan ke papan relay untuk mengaktifkan relay yang sesuai dengan perangkat elektronika yang akan dikendalikan. Ketika data yang dikirimkan oleh modul Arduino UNO R3 sampai ke salah satu relay yang bersesuaian dengan perangkat elektronika yang ingin dikendalikan, maka relay akan secara otomatis menghidupkan atau mematikan alat elektronik tersebut.

\section{Prosedur Penelitian}

Penelitian ini dilakukan di laboratorium Fisika Sekolah Tinggi Keguruan Dan Ilmu Pendidikan (STKIP) Bima. Peralatan yang dibuat dilakukan pengujian meliputi: pengujian sensor PIR, pengujian minimum sistem arduino ATMega328, pengujian jarak.

1. Memulai mempersiapkan alat dan bahan.

2. Melakukan pengambilan data jarak titik sensor dan objek.

3. Menunjukan cara kinerja pengujian sensor dengan mendekatkan dengan objek untuk mendapatkan keakuratan sensor dalam membaca jarak objek tersebut.

4. Menghitung manual waktu yang dibutuhkan sensor padajarak $1 \mathrm{~m}, 2 \mathrm{~m}, 3 \mathrm{~m}, 4 \mathrm{~m}, 5 \mathrm{~m}$.

5. Pengujian Keakurasian Sensor Terhadap Perubahan jarak. Pengujian ini dilakukan di laboratorium dengan mengatur perubahan jarak, sehingga akan menyebabkan perubahan yang dibaca oleh sensor.

6. Sistem aktif jika poin 1 sampai 6 berjalan dengan baik dan akan diulangi sebanyak 5 kali. 
7. Lakukan langkah yang sama untuk menguji keakuarasian sensor terhadap perubahan sudut.

8. Selesai.

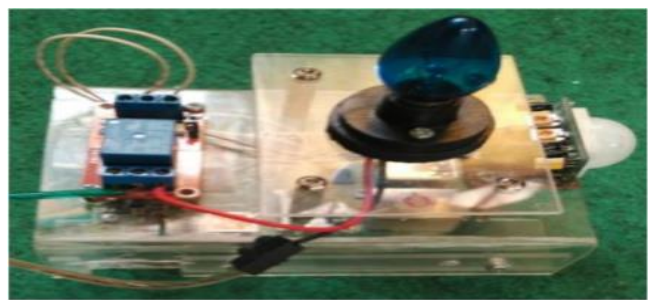

Gambar 3. Prosedur Penelitian

\section{Simulasi Prototype Sistem Lampu Otomatis Berbasis Ardiuno Menggunakan Modul PIR HC 501}

Simulasi Prototype Sistem Lampu Otomatis Berbasis Ardiuno Menggunakan Modul PIR HC 501

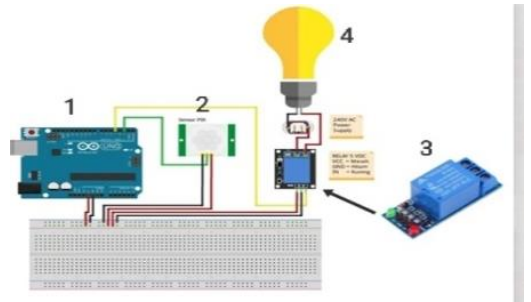

Gambar 3 .Simulasi perancangan prototype

\section{Keterangan:}

1. Arduino uno sebagai media pemroses data.

2. Sensor PIR Media input (sensor gerak).

3. Modul Relay Saklar otomatis.

Lampu Media output.

\section{HASIL DAN PEMBAHASAN}

Pada penelitian ini penulis menggunakan metode penelitian eksperimen dengan melakukan 3 kali percobaan dengan menggunakan teman sejawat sebagai objek dan menggunakan stopwatch untuk mengukur waktu.

\section{Perancangan Alat Dan Pengumpulan Data}

Dalam penelitian ini dibutuhkan sejumlah perangkat keras (hardware) maupun perangkat lunak (software) untuk merancang dan pengimplementasia sistem lampu otomatis yang diusulkan. Untuk perancangan alat hal pertama yang dilakuakan yaitu, mengidentifikasi masalah, mengumpulkan data, membuat konsep dan desain alat, kemudian pengumpulan bahan. Setelah semua bahan yang diperlukan sudah siap maka dilakukan perakitan alat, lalu menguji kemampuan alat yang dibuat, kemudian menyimpulkan hasil dari pengujian. Pengujian meliputi: pengujian sensor PIR, pengujian minimum sistem arduino ATMega328, pengujian jarak.

Pengambilan data pada sistem lampu otomatis ini dilakukan pengukuran kepekaan sensor pada jarak 1 meter,
2 meter, 3 meter, 4 meter, dan 5 meter. Selain pengukuran kepekaan sensor pada jarak diukur kepekaan sensor terhadap sudut $0^{\circ}, 30^{\circ}$, dan $60^{\circ}$. Pengambilan data dilakukan pengulangan sebanyak 3 kali.Dari hasil pengambilan data yang dilakukan diperoleh waktu kepekaan terhadap objek dengan jarak dan sudut yang sudah ditentukan. Perancangan hardware pada sistem lampu otomatis ini terdapat pada tabel di bawah ini:

Tabel 3 Hasil Pengujian Sudut Pada Sensor PIR

\begin{tabular}{cccccccccccc}
\hline No & sudut & \multicolumn{4}{c}{ Respon Sensor } & \multicolumn{5}{c}{ Waktu (s) Deteksi } \\
\cline { 3 - 7 } & & \multicolumn{4}{c}{ Pengulangan $(\mathbf{m})$} & & & & & \\
& & $\mathbf{1}$ & $\mathbf{2}$ & $\mathbf{3}$ & $\mathbf{4}$ & $\mathbf{5}$ & & & & & \\
\hline $\mathbf{1}$ & $0^{\circ}$ & ya & ya & ya & ya & ya & 5,2 & 5,1 & 10,03 & 7,5 & 7,01 \\
$\mathbf{2}$ & $30^{\circ}$ & ya & ya & tdk & tdk & tdk & 3,45 & 5,05 & - & - & - \\
$\mathbf{3}$ & $60^{\circ}$ & tdk & tdk & tdk & tdk & tdk & - & - & - & - & - \\
\hline
\end{tabular}

Pada sudut $0^{\circ}$ dilakukan 5 kali percobaan berdasarkan jarak yang ditentukan yaitu jarak 1 meter, 2 meter, 3 meter, 4 meter, dan 5 meter. Pada sudut $0^{\circ}$ yaitu tepat didepan sensor jarak maksimum yang mampu dideteksi oleh sensor yaitu 5 meter. Pada sudut $30^{\circ}$ jarak maksimum yang mampu dideteksi oleh sensor adal 2 meter. Pada jarak 3,4 dan 5 meter sensor PIR tidak mampu mendeteksi objek karna sensor butuh diistirahatkan sekitar 10 detik untuk mengidentifikasi objek kembali. Sedangkan pada sudut $60^{\circ}$ sensor tidak merespon objek sama sekali karna semakin lebar sudut maka semakin lemah untuk mendeteksi objek. Semakin lebar sudutnya maka semakin lemah sensor mendeteksi sebuah objek yang memiliki infra merah. pada dasarnya manusia memiliki infra merah yang memancar pada pada tubuhnya tapi pada sensor PIR ketika objek diletakkan pada sudut $60^{\circ}$ sensor tidak mampu mendeteksi adanya ifra merah, mungkin sensor mendeteksi tapi hanya saja infra merah yang terpancar itu lemah.

Pada saat melakukan penelitian disetiap jarak dan sudut yang digunakan sensor PIR tidak terlalu merespon sebuah objek jika objek tersebut tidak dilakukan gerakangerakan sehingga sensor mampu mendeteksi objek tersebut. Saat penelitian penulis membutuhkan teman sejawat untuk ditempatkan sebagai objek dan untuk menghitung waktu menggunakan stopwacth. Pada penelitian ini penggunaan sensor PIR dan Arduino uno dinilai belum efektif karna banyak ditemukan kekurangan, salah satunya sensor PIR tidak cocok untuk digunakan sebagai sistem lampu otomatis karna sensor ini memiliki setting time delay sehingga pada penelitian ini untuk membuat lampu menyala membutuhkan waktu selama \pm 20 detik. Penggunaan stopwacth pada penelitian ini dilai tidak efektif karena saat lampu sudah menyal tapi waktu belum disetel/diatur, dengan demikian penghitungan waktu dengan cara manual kurang efektif.. 


\section{KESIMPULAN}

Hasil pengujian menunjukkan bahwa sistem kerja rangkaian lampu otomatis yang disasarkan terhadap ruangan kamar mandi yang memiliki sistem input yang terhubung pada Arduino Uno, sistem yang dimiliki yakni sensor Passive Infra Red (PIR) sebagai input sistem yang otomatis yang bertanggungjawab terhadap pembacaan objek pada saat manusia terdeteksi masuk kedalam satu ruangan kamar mandi melalui radiasi infra red yang dihasilkan objek tersebut. Arduno Uno mendapat input dari sensor Passive Infra Red (PIR) kemudian akan diteruskan di relay yang menghasilkan output berupa lampu kamar mandi yang menyala yang akan distabilkan oleh infra red. Berdasarkan hasil penelitian pada jarak 1 meter dan sudut $0^{\circ}$ yakni tepat didepan sensor waktu sensor mendeteksi adana infra merah pada objek butuh beberapa gerakan objek agar sensor mampu mendeteksi objek tersebut, sedangkan semakin lebarnya sudut daya deteksi sensor sangat lemah sehingga tidak mampu mendeteksi adanya infra merah.

\section{DAFTAR PUSTAKA}

[1] Desmira, Didik Aribowo, Widhi Dwi Nugroho dan Sutarti, "Penerapan Sensor Passive Infrared (Pir) Pada Pintu Otomatis Di Pt Lg Electronic Indonesia", Jurnal PROSISKO Vol. 7 No. 1 Maret 2020

[2] Desy Santi Djaeng, Dwi Astutik, "Rancang Bangun Lampu Otomatis Dengan Sensor Passive Infra Red (PIR) Berbasis Raspberry Pi”. Jurnal Elektronik Sistem Informasi dan Komputer, Vol.3 No.2 JuliDesember 2017.

[3] Yulia Misni. Universitas Sumatera Utara, "Rancang Bangun Alat Kendali Lampu Menggunakan Sensor Tepuk Berbasis arduino Uno",2017. 